Electronic supplementary information:

\title{
Modification of the fluorinated tin oxide/electron transporting material interface by a strong reductant and its effect on perovskite solar cell efficiency
}

Federico Pulvirenti, ${ }^{a}$ Berthold Wegner, ${ }^{b}$ Nakita K. Noel, ${ }^{c}$ Giulio Mazzotta, ${ }^{c}$ Rebecca Hill, ${ }^{a}$ Jay B. Patel, ${ }^{c}$ Laura M. Herz, ${ }^{c}$ Michael B. Johnston, ${ }^{c}$ Moritz Riede, ${ }^{c}$ Henry J. Snaith, ${ }^{c}$ Norbert Koch, ${ }^{b}$ Stephen Barlow, ${ }^{a}$ and Seth R. Marder $^{\mathrm{a} *}$

${ }^{a}$ School of Chemistry and Biochemistry and Center for Organic Photonics and Electronics (COPE), Georgia Institute of Technology GA, Atlanta 30332-0400, USA. Email: seth.marder@chemistry.gatech.edu

${ }^{b}$ Institut für Physik \& IRIS Adlershof, Humboldt-Universität zu Berlin, Brook-Taylor-Str. 6, D-12489 Berlin, Germany; and Helmholtz-Zentrum Berlin für Materialien und Energie GmbH, Albert-Einstein-Str. 15, 12489 Berlin, Germany

${ }^{C}$ Clarendon Laboratory, Department of Physics, University of Oxford, Parks Road, Oxford, OX1 3PU, UK

\section{Contents}

1. UPS and IPES data (Figures S1-2)

2. XPS data (Figures S3-5; Tables S1-3; Discussion of XPS Rh 3d peak assignment) p2

3. UV-vis-NIR spectra (Figures S6-9)

4. Solar-cell data (Figure S10; Tables S4)

5. References for ESI

\section{UPS and IPES data}

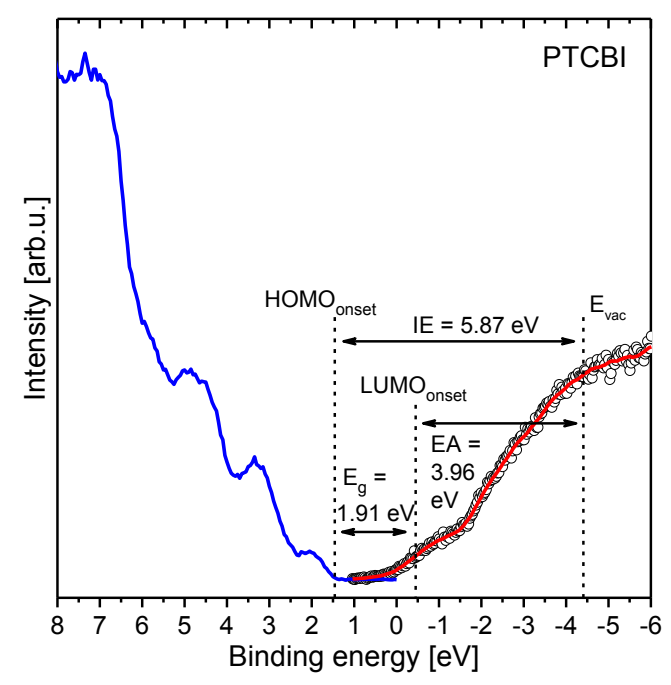

Figure S1. Electronic structure of pure PTCBI, obtained via UPS (blue curve) and IPES (red curve). The optical band gap was measured to be $1.7 \mathrm{eV}$; the ionization energy $(5.87 \mathrm{eV})$ is similar to values reported in the literature $(6.2 \mathrm{eV}) .{ }^{1} \mathrm{UPS}$ was performed before IPES. The resolution of the IPES setup is $1.3 \mathrm{eV}$ and was determined from the broadening of the Fermi level of a gold reference. To account for this low resolution, the onset of the LUMO level measured by IPES was corrected by 700 meV assuming the full width at half maximum (FWHM) of the LUMO to be the same as that of the HOMO, which was measured by UPS (600 meV). The correction was performed following a previously described method. ${ }^{2}$ 

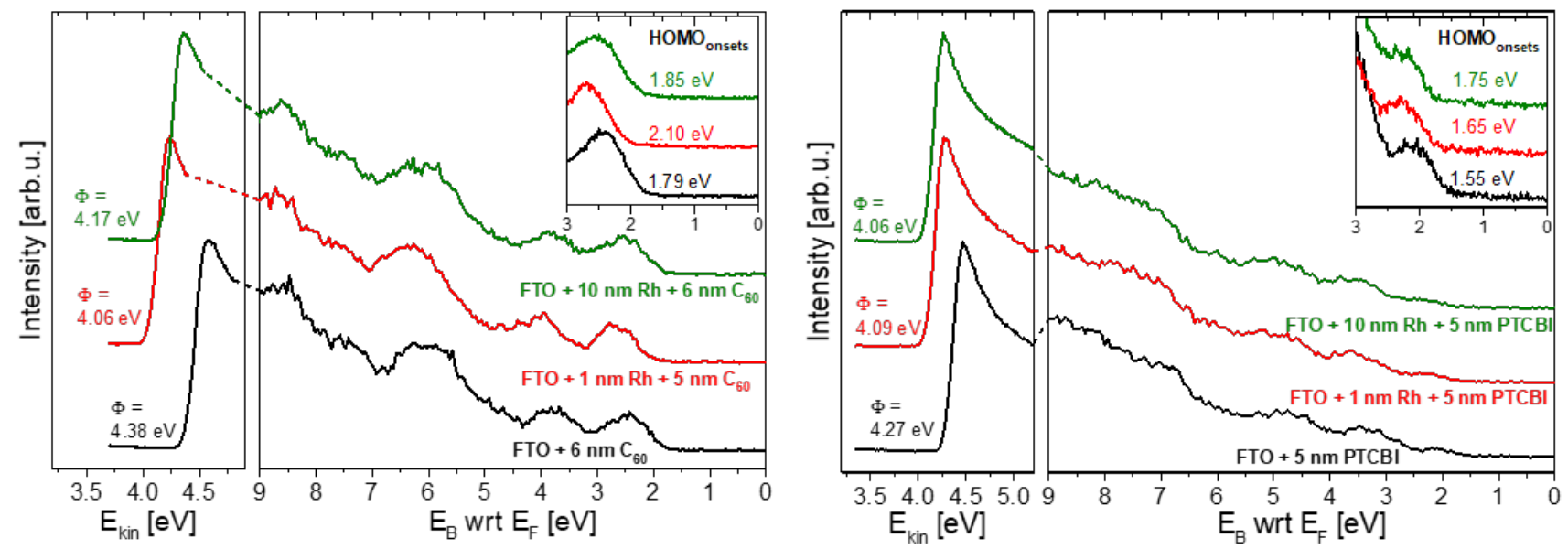

Figure S2. UPS spectra of FTO/ETM and $(\mathrm{RhCp} * \mathrm{Cp})_{2}$ modified-FTO/ETM with varying thickness of the $(\mathrm{RhCp} * \mathrm{Cp})_{2}$ interlayer. The ETMs used were $\mathrm{C}_{60}$ (left) and PTCBI (right). The WF of FTO/1 nm (RhCp*Cp) $2 / 5 \mathrm{~nm} \mathrm{C}_{60}$ is lower than that of $\mathrm{FTO} / 1 \mathrm{~nm}\left(\mathrm{RhCp}^{*} \mathrm{Cp}\right)_{2} / 6 \mathrm{~nm} \mathrm{C} \mathrm{C}_{60}$ in agreement to the model proposed by Oehzelt et al. ${ }^{3}$ Note the different thickness of $\mathrm{C}_{60}$ for these specific samples.

\section{XPS data}

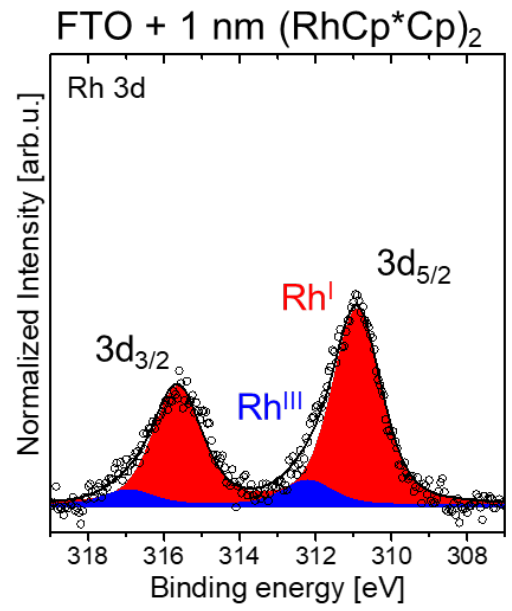

Figure S3. XPS spectrum of modified FTO with a $1 \mathrm{~nm}$-thick layer of (RhCp*Cp) $)_{2}$. The intensity of the Rh $3 \mathrm{~d}$ peaks was normalized to the area of the Sn 3d peaks associated with the FTO substrate. 

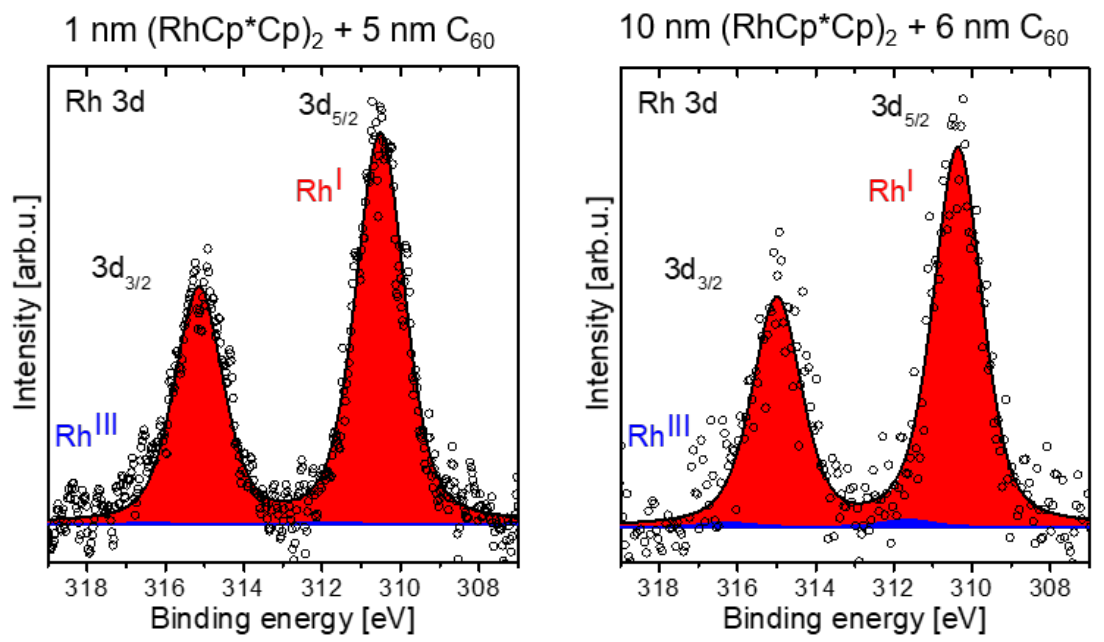

$10 \mathrm{~nm} 5 \%$ doped $\mathrm{C}_{60}$

$1 \mathrm{~nm}\left(\mathrm{RhCp}{ }^{*} \mathrm{Cp}\right)_{2}+5 \mathrm{~nm}$ PTCBI

$10 \mathrm{~nm}\left(\mathrm{RhCp}^{*} \mathrm{Cp}\right)_{2}+5 \mathrm{~nm}$ PTCBI
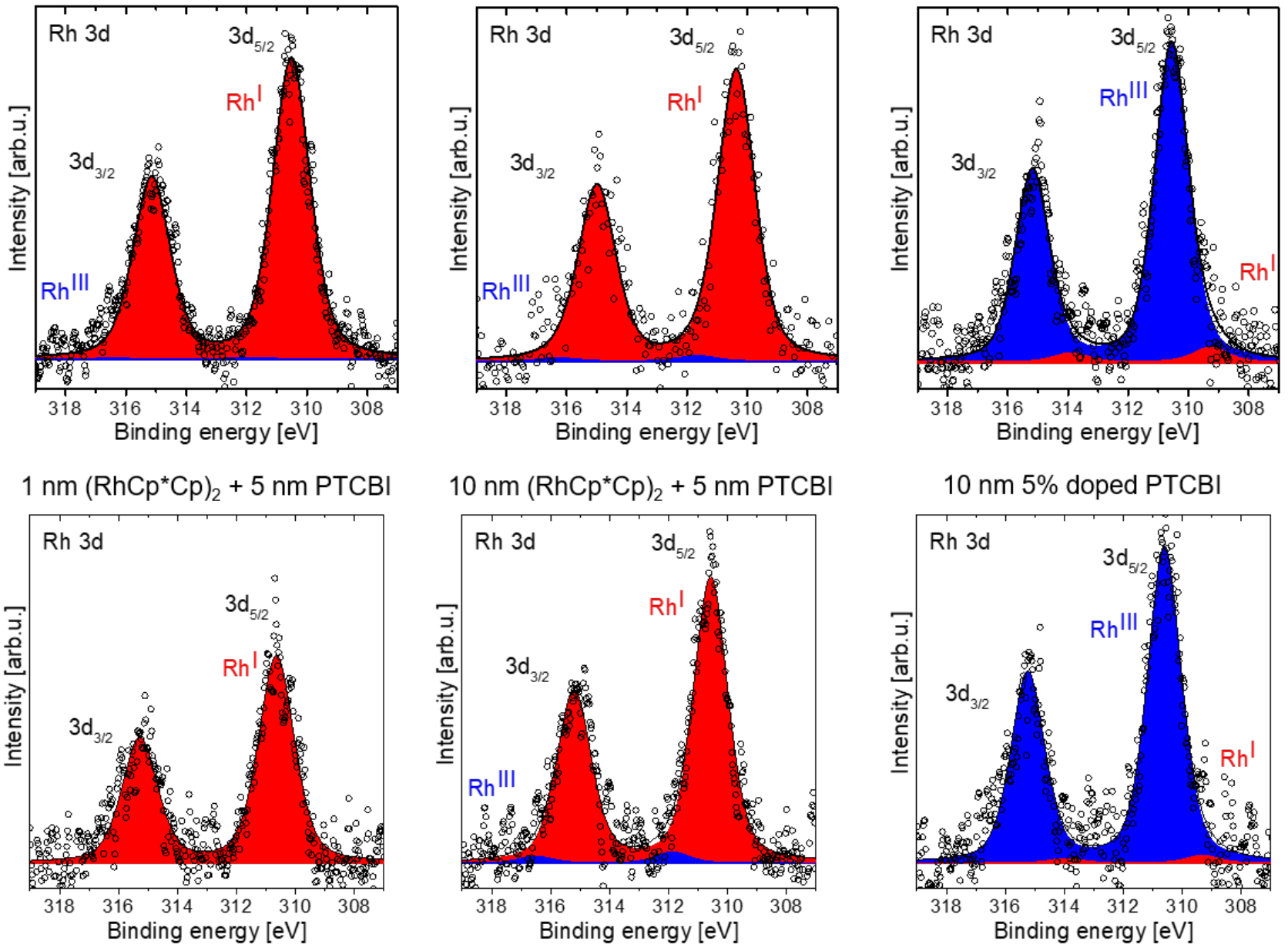

$10 \mathrm{~nm} 5 \%$ doped PTCBI

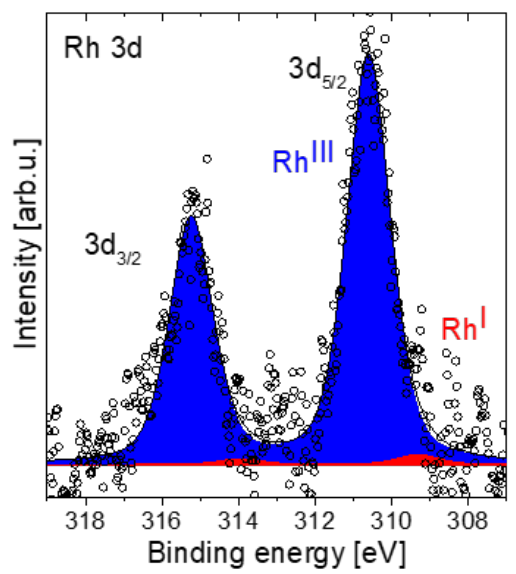

Figure S4. XPS Rh 3d scans of FTO/1-10 nm (RhCp*Cp) ${ }_{2} /$ ETM and FTO/ ETM coevaporated with $(\mathrm{RhCp} * \mathrm{Cp})_{2}$.

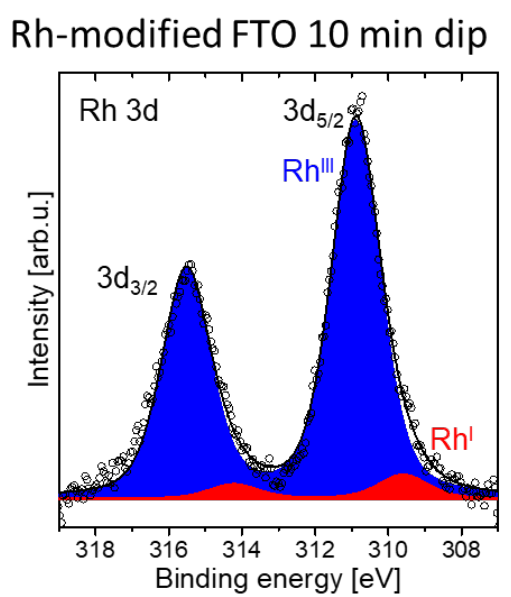

Figure S5. XPS Rh 3d scans of FTO modified by dipping the metal oxide in a $2 \mathrm{mM}(\mathrm{RhCp} * \mathrm{Cp})_{2}$ toluene solution for 10 minutes, and by rinsing the modified FTO three times with pure toluene. 
Table S1. XPS binding energies and peak ratios for ( $\mathrm{RhCp} * \mathrm{Cp})_{2}$-covered clean FTO. All values are in eV (except ratios). The position of the $\mathrm{Rh}^{\prime \prime \prime} 3 \mathrm{~d}$ peaks was fixed to be at a distance of $1.3 \mathrm{eV}$ from the $\mathrm{Rh}^{\prime} 3 \mathrm{~d}$ peaks to allow consistent fitting. ${ }^{1}$

\begin{tabular}{|c|c|c|c|c|c|c|c|}
\hline Binding energy & $\operatorname{Sn} 3 d_{5 / 2}$ & $\mathrm{O} \mathrm{1s}$ & C 1s & $\mathrm{Rh}^{1} 3 \mathrm{~d}_{5 / 2}$ & $\mathrm{Rh}^{\mathrm{III}} 3 \mathrm{~d}_{5 / 2}$ & $\mathrm{Rh}^{\mathrm{III}} / \mathrm{Rh}^{\mathrm{I}}$ & $\mathrm{Rh} / \mathrm{Sn}$ \\
\hline FTO & 487.22 & 531.33 & 285.62 & -- & -- & -- & -- \\
\hline $\mathrm{FTO}+1 \mathrm{~nm}(\mathrm{RhCp} * \mathrm{Cp})_{2}$ & 487.27 & 531.32 & 286.17 & 310.91 & 312.21 & 0.13 & $1.6 \times 10^{-2}$ \\
\hline $\mathrm{FTO}+10 \mathrm{~nm}(\mathrm{RhCp} * \mathrm{Cp})_{2}$ & 487.29 & 531.33 & 286.23 & 310.82 & 312.12 & 0.14 & $3.5 \times 10^{-2}$ \\
\hline $\begin{array}{l}\text { FTO }+10 \text { min dipped } \\
\left(\mathrm{RhCp}^{*} \mathrm{Cp}\right)_{2}{ }^{\mathrm{a}}\end{array}$ & 487.23 & - & 286.23 & 309.72 & 311.02 & 8.33 & 0.057 \\
\hline
\end{tabular}

${ }^{\mathrm{a}}$ Modified by dipping for $10 \mathrm{~min}$ in a $2 \mathrm{mM}$ solution of $\left(\mathrm{RhCp}^{*} \mathrm{Cp}\right)_{2}$ in toluene, followed by three rinsing cycles with pure toluene

Table S2. XPS binding energies and peak ratios for $\mathrm{C}_{60}$, bilayers of $(\mathrm{RhCp} * \mathrm{Cp})_{2}$ and $\mathrm{C}_{60}$, and coevaporated $\mathrm{C}_{60}$ and dopant. The Rh/C ratio of 0.003 for the coevaporated ETM and dopant was used to calculate the actual doping concentration of $10 \%$.

\begin{tabular}{|c|c|c|c|c|c|c|}
\hline Binding energy & $\operatorname{Sn} 3 d_{5 / 2}$ & $\mathrm{C} 1 \mathrm{~s}$ & $\mathrm{Rh}^{\mathrm{I}} 3 \mathrm{~d}_{5 / 2}$ & $\mathrm{Rh}^{\mathrm{III}} 3 \mathrm{~d}_{5 / 2}$ & $\mathrm{Rh}^{\mathrm{III}} / \mathrm{Rh}^{\mathrm{I}}$ & $\mathrm{Rh} / \mathrm{C}$ \\
\hline $6 \mathrm{~nm} \mathrm{C}_{60}$ & 487.30 & 285.22 & -- & -- & -- & -- \\
\hline $1 \mathrm{~nm}(\mathrm{RhCp} * \mathrm{Cp})_{2}+5 \mathrm{~nm} \mathrm{C}_{60}$ & 487.21 & 285.41 & 310.52 & -- & -- & 0.004 \\
\hline $10 \mathrm{~nm}(\mathrm{RhCp} * \mathrm{Cp})_{2}+5 \mathrm{~nm} \mathrm{C}_{60}$ & 487.21 & 285.28 & 310.36 & 311.66 & 0.02 & 0.002 \\
\hline $5 \%$ doped $\mathrm{C}_{60}$ & -- & 285.38 & 309.26 & 310.56 & 21.8 & 0.003 \\
\hline
\end{tabular}

Table S3. XPS binding energies and peak ratios for PTCBI, bilayers of ( $\mathrm{RhCp} * \mathrm{Cp})_{2}$ and PTCBI, and coevaporated PTCBI and dopant. The Rh/N ratio of 0.04 for the coevaporated ETM and dopant was used to calculate the actual doping concentration of $8 \%$.

\begin{tabular}{|c|c|c|c|c|c|c|c|}
\hline Binding energy & Sn $3 d_{5 / 2}$ & $\mathrm{C} 1 \mathrm{~s}$ & $\mathrm{~N} 1 \mathrm{~s}$ & $\mathrm{Rh}^{\mathrm{I}} 3 \mathrm{~d}_{5 / 2}$ & $\mathrm{Rh}^{\mathrm{III}} 3 \mathrm{~d}_{5 / 2}$ & $\mathrm{Rh}^{\mathrm{III}} / \mathrm{Rh}^{\mathrm{I}}$ & $\mathrm{Rh} / \mathrm{N}$ \\
\hline $5 \mathrm{~nm}$ PTCBI & 487.14 & 285.23 & 398.90 & -- & -- & -- & -- \\
\hline $\begin{array}{l}1 \mathrm{~nm}\left(\mathrm{RhCp}^{*} \mathrm{Cp}\right)_{2}+5 \\
\mathrm{~nm} \text { PTCBI }\end{array}$ & 487.12 & 285.30 & 398.98 & 310.57 & 311.87 & 0.10 & 0.03 \\
\hline $\begin{array}{l}10 \mathrm{~nm}(\mathrm{RhCp} * \mathrm{Cp})_{2}+5 \\
\mathrm{~nm} \text { PTCBI }\end{array}$ & 487.16 & 285.29 & 398.96 & 310.58 & 311.88 & 0.04 & 0.02 \\
\hline $5 \%$ doped PTCBI & -- & 285.30 & 398.98 & 309.32 & 310.62 & 40.6 & 0.04 \\
\hline
\end{tabular}

\section{Discussion of XPS Rh 3d peak assignment}

The Rh $3 d$ ionization is split into $3 d_{5 / 2}$ and $3 d_{3 / 2}$ peaks by spin-orbit coupling; the following discussion and the binding energies (BEs) reported in Tables S1-3 are focused on the $\mathrm{Rh} 3 \mathrm{~d}_{5 / 2}$ component but the trends apply equally to the Rh $3 d_{3 / 2}$. In both the present study and previous work, two chemically distinct species are often present in $(R h C p * C p)_{2}-$ containing samples, differing in $\mathrm{Rh} 3 \mathrm{~d}_{5 / 2}$ (and $3 \mathrm{~d}_{3 / 2}$ ) BE by ca. $1.3 \mathrm{eV}$. $^{4-5}$ These are assigned to the unreacted neutral dimer, $(\mathrm{RhCp} * \mathrm{Cp})_{2}$, and the monomer cation, $\mathrm{RhCp}^{*} \mathrm{Cp}^{+}$, that is known to be formed on oxidation of the dimer, ${ }^{6}$ with the lower BE signal being assigned to the former, which is formally $\mathrm{Rh}^{\prime}$, and the higher BE signal to the latter, which is formally $\mathrm{Rh}^{\text {III }}$. However, since this difference in BEs is relative small (although the formal oxidation states are $1+$ and $3+$, there is considerable covalency and charge delocalization onto the ligands in these species), differences in the immediate environment of the Rh species can have comparable effects on the BE to the oxidation state; this has been seen in previous studies ${ }^{4-5}$ and the present work.

Table S1 compares data for a dimer solution deposited on FTO, followed by washing with toluene to remove most of the unreacted $(\mathrm{RhCp} * \mathrm{Cp})_{2}$, which leaves primarily $\mathrm{Rh}^{\prime \prime \prime}$ cations (originated from dopants that have transferred electrons to the oxide) covering most of the FTO surface, with data for thick evaporated layers of the dimer, where only a small fraction is expected to be oxidized to the cation. This illustrates that the BEs depend on the details of the environment with both high- and low-BE components, assigned to $\mathrm{Rh}^{\text {III }}$ and $\mathrm{Rh}^{\prime}$ respectively, being seen at lower BEs in the thin film. Tables S2 and S3 indicates that similar $\mathrm{Rh}^{\prime}$ and $\mathrm{Rh}^{\prime \prime \prime}$ BEs for thick evaporated films in the presence of ETM overlayers as the uncovered thick layers in Table 1. On the other hand, for coevaporated dimer:ETM films, where owing to the high EA of the ETMs (>> $3 \mathrm{eV}$ ) most the dimer is expected to be converted to Rh" monomer cations, the BEs for both $\mathrm{Rh}^{\prime}$ and $\mathrm{Rh}^{\prime \prime \prime}$ components are similar to, but a little lower than the corresponding values for the monolayer films on FTO, and considerable lower than those for the thick films. The differences in BEs for the two 
components between samples presumably arise from the large differences in chemical environments: in the monolayers on FTO the dopant molecules and ions are all in close proximity to the negatively charged oxide film, in coevaporated films the dopant species will likely be in close proximity to both neutral and negatively charged ETM molecules, and in the thick film structures (both with and without ETM overlayers), most dopant species will be surrounded by neutral dopant molecules.

\section{UV-vis- NIR spectra}

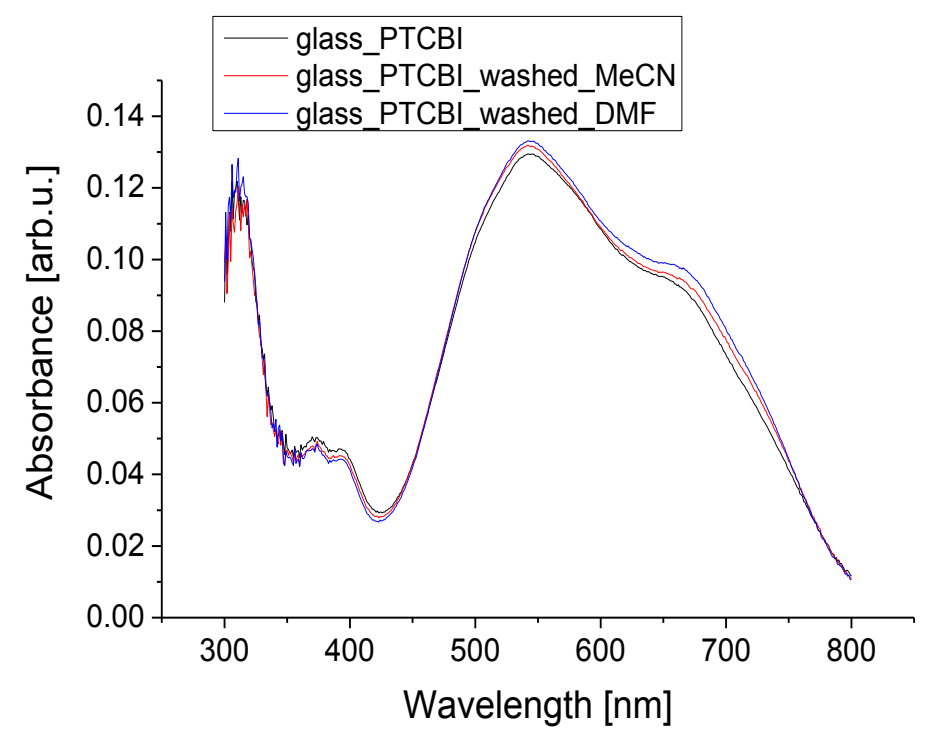

Figure S6. UV-vis spectra of 15-nm thick PTCBI films on glass before and after sequential spin-coating of acetonitrile and dimethylformamide.
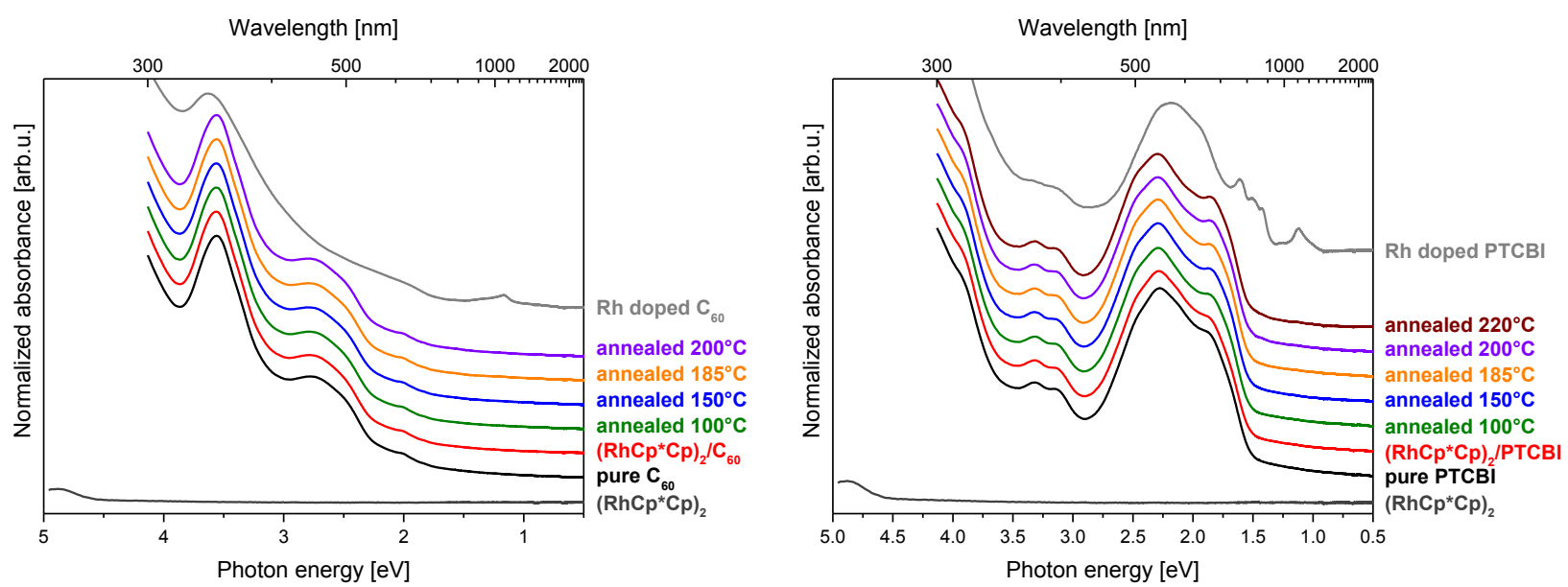

Figure S7. UV-vis-NIR absorption spectra for pure ETM, $(\mathrm{RhCp} * \mathrm{Cp})_{2}$ modified-FTO/ETM annealed at increasing temperatures, and $(\mathrm{RhCp} * \mathrm{Cp})_{2}$ co-evaporated with ETM with a doping concentration of around $10 \%$. 


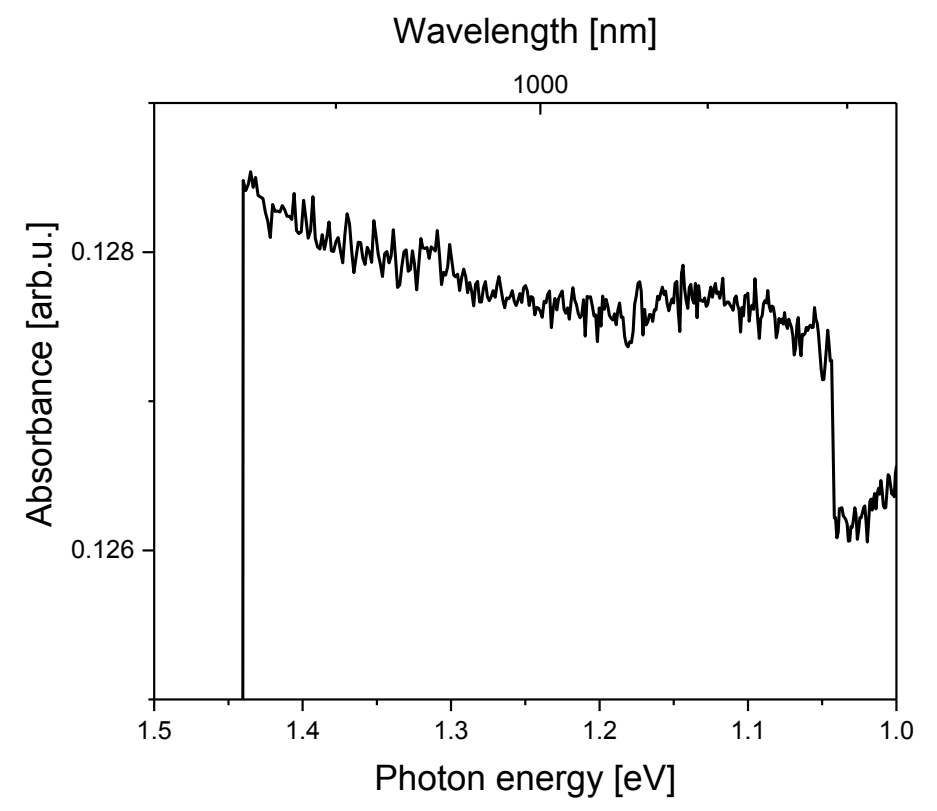

Figure S8. Absorption of the reference box used to perform UV-vis-NIR absorption spectroscopy on samples containing $\left(\mathrm{RhCp}^{*} \mathrm{Cp}\right)_{2}$. Since there are no absorption features of the reference box in the range of $1.04 \mathrm{eV}$ to $1.44 \mathrm{eV}$, features in this range can be assigned to sub-bandgap features of the samples. Abrupt signal changes at $1.04 \mathrm{eV}$ and $1.44 \mathrm{eV}$ are artifacts of the spectrometer due to detector and grating changes.

Wavelength [nm]

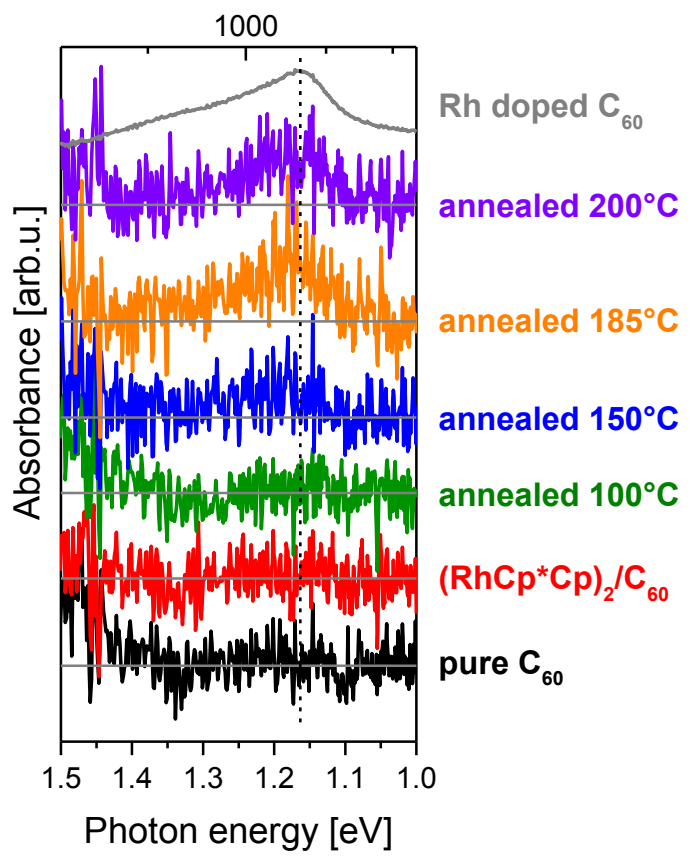

Wavelength [nm]

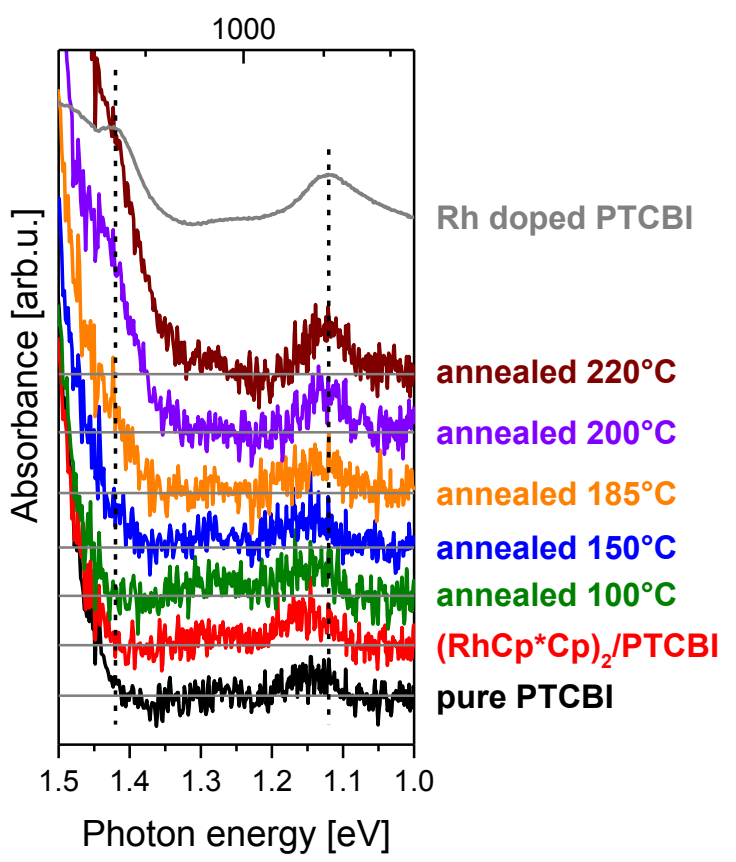

Figure S9. Raw NIR absorption spectra for pure ETM, $\mathbf{1}_{\mathbf{2}}$-modified FTO/ETM annealed at increasing temperatures, and $\mathbf{1}_{\mathbf{2}}$ co-evaporated with ETM. The ETMs used were $\mathrm{C}_{60}$ (left) and PTCBI (right). The doping concentrations for coevaporated ETMs are calculated from the deposition rates to be $13 \%$ for $\mathrm{C}_{60}$ and $17 \%$ for PTCBI. 


\section{Solar-cell data}
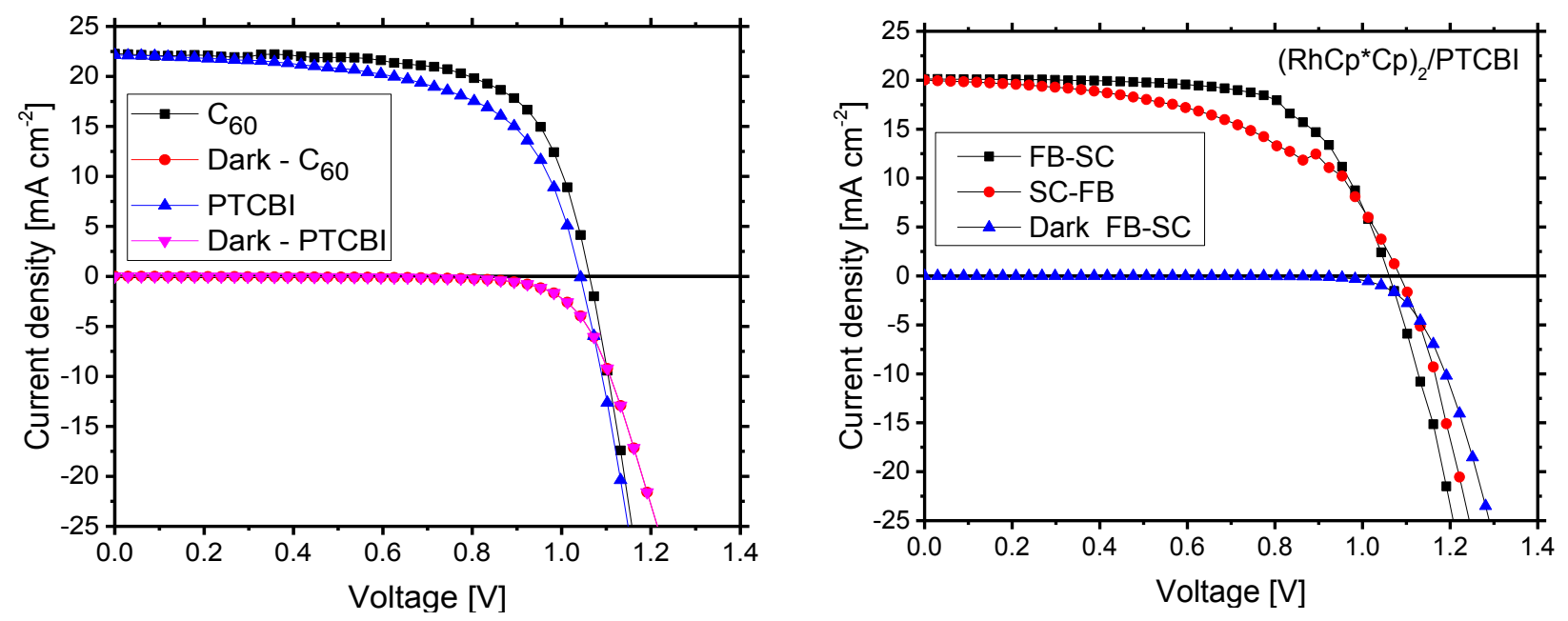

Figure S10. Current density-voltage characteristics for the best performing solar cells fabricated using $\mathrm{C}_{60}$ and PTCBI as ETMs (center-right), and with PTCBI deposited on (RhCp*Cp) $)_{2}$-modified FTO. FB stands for forward bias, and SC stands for short circuit. These solar cells were fabricated using a methylamine-acetonitrile solvent system in which the perovskite precursors salts are dissolved.

Table S4. Device performance parameters of champion solar cells with solution-processed $\mathrm{CH}_{3} \mathrm{NH}_{3} \mathrm{Pbl}_{3}$.

\begin{tabular}{lccccc}
\hline Cell type & $\mathrm{J}_{\text {sc }}\left(\mathrm{mA} \mathrm{cm}^{-2}\right)$ & $\mathrm{V}_{\text {oc }}(\mathrm{V})$ & $\mathrm{FF}(\%)$ & PCE $(\%)$ & $\eta_{\text {MPP }}(\%)$ \\
\hline $\mathrm{C}_{60}$ & 22.3 & 1.07 & 68 & 15.7 & 16 \\
PTCBI & 22.2 & 1.04 & 61 & 13.7 & 12.7 \\
$10 \mathrm{~nm}\left(\mathrm{RhCp}^{*} \mathrm{Cp}\right)_{2} /$ PTCBI & 20.1 & 1.07 & 67 & 14.6 & 14.2 \\
\hline
\end{tabular}

\section{References for ESI}

1. I. G. Hill, A. Kahn, Z. G. Soos and J. R. A. Pascal, Chem. Phys. Lett., 2000, 327, 181-188.

2. S. Krause, M. B. Casu, A. Schöll and E. Umbach, New J. Phys., 2008, 10, 085001.

3. M. Oehzelt, N. Koch and G. Heimel, Nat. Commun., 2014, 5, 4174.S.

4. K. Akaike, M. V. Nardi, M. Oehzelt, J. Frisch, A. Opitz, C. Christodoulou, G. Ligorio, P. Beyer, M. Timpel, I. Pis, F. Bondino, K. Moudgil, S. Barlow, S. R. Marder and N. Koch, Adv. Funct. Mater., 2016, 26, 24932502.

5. S. A. Paniagua, J. Baltazar, H. Sojoudi, S. K. Mohapatra, S. Zhang, C. L. Henderson, S. Graham, S. Barlow and S. R. Marder, Mater. Horiz., 2014, 1, 111-115.

6. S. Guo, S. K. Mohapatra, A. Romanov, T. V. Timofeeva, K. I. Hardcastle, K. Yesudas, C. Risko, J.-L. Brédas, S. R. Marder and S. Barlow, Chem. Eur. J., 2012, 18, 14760-14772. 